12 - ORIGINAL ARTICLE

ALIMENTARY TRACT

\title{
Effects of preoperative irradiation using fractioned electron beam on the healing process of colocolonic anastomosis in rats undergoing early and late surgical intervention ${ }^{1}$
}

\author{
Joaquim Simões Neto', José Alfredo dos Reis Neto"I, Delcio Matos ${ }^{\text {III }}$
}

${ }^{\mathrm{I}}$ Fellow Master degree, Postgraduate Program in Surgical Gastroenterology, UNIFESP, Sao Paulo-SP. Assistant Professor, Department of Surgery, PUCCAMP, Campinas-SP, Brazil. Acquisition and interpretation of data, involved with technical procedures, manuscript writing.

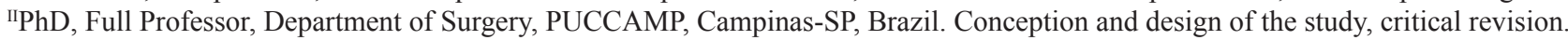

IIIFull Professor, Division of Surgical Gastroenterology, Department of Surgery, UNIFESP and Metropolitan University of Santos. Coordinator Postgraduate Program in Surgical Gastroenterology, UNIFESP, Sao Paulo-SP, Brazil. Conception, design and supervised all phases of the study, manuscript writing, critical revision.

\begin{abstract}
PURPOSE: To investigate the effects of preoperative fractioned irradiation using an electron beam on the healing process of colocolonic anastomoses in rats that underwent early and late surgical intervention.

METHODS: Thirty Wistar rats, distributed as follows: group A (surgery only), group B (fractionated irradiation for 30 days (if), surgery seven days after the end of it), group C (if for 30 days, and surgery after 30 days of termination). On the seventh postoperative day the anastomotic segment analysis was taken, using tension tests, histology and collagen deposition evaluation by computerized analysis.

RESULTS: Regarding the tension resistance of the anastomosis, there were no statistical differences ( $p=0.42)$. However, a significant increase in cells number in the inflammatory infiltrate in the group with a longer interval between surgery and pre op radiation $(\mathrm{p}<0.05)$. The collagen concentration had no significant variance.

CONCLUSION: The irradiation in divided doses increased local inflammatory cellularity when the surgery was performed later. This result did not affect the increase of complications, nor on the local concentration of collagen, achieving similar clinical outcomes.
\end{abstract}

Key words: Dose Fractionation. Anastomosis, Surgical. Colon. Wound Healing. Surgical Procedures, Operative. Rats. 


\section{Introduction}

Rectal neoplasia is a frequent infirmity, in which surgical treatment has presented up to $30 \%$ local recurrence. Through introduction of the concept of total resection of the mesorectum, it has been demonstrated that, when the oncologic precepts of such cases are respected, the local recurrence rate is drastically reduced $(03-06 \%)^{1}$.

With the use of neoadjuvant therapy, these values have also been observed in more advanced stages of the neoplastic lesion, and the disease-free period is significantly longer ${ }^{2}$. Another advantage of preoperative radiotherapy is its capacity to sterilize tumor cells in perirectal fat, thereby decreasing locoregional reoccurrence ${ }^{3}$.

However, although the beneficial role of neoadjuvant therapy has been well established in the literature, controversy exists regarding the best time for surgical intervention after preoperative fractioned irradiation. In surgery to treat neoplasia performed 4-8 weeks after irradiation, lower toxicity and better capacity for tumor cytoreduction have been observed ${ }^{4,5}$.

The main advantage of early intervention, i.e. with an interval of less than ten days from the last irradiation session, is that this is a time at which the fibrotic and inflammatory reactions caused by the neoadjuvant process are still at an initial stage and, furthermore, do not interfere with the technical results. The rates of complications, such as dehiscence of the anastomosis, are significantly similar to the rates in groups that did not undergo radiotherapy ${ }^{6,7}$

In an experimental study on rats, Lopes Paulo ${ }^{8}$ found that the deleterious effect of the irradiation caused significant changes to the tissue repair process and to the collagen concentration and tension strength of the anastomosis, thus contributing towards an unfavorable result in the irradiated group. Similar results have been observed by other authors ${ }^{6}$, and this partly justifies postponement of surgery in clinical practice, to a time more than four weeks after irradiation, thereby diminishing the inherent complications of this procedure. Stevens et al. ${ }^{9}$ even recommended that the colorectal anastomosis should be protected by means of a temporary colostomy, because of the observed frequency of dehiscence.

The main discussion about the interval between preoperative irradiation and surgery is based on the inherent risk of complications from the colorectal anastomosis. Several groups have presented comparative studies on the risks of dehiscence of the anastomosis ${ }^{10}$, but without analyzing the effects of this factor relating to a prolonged fractioned irradiation strategy ${ }^{11}$.

The objective of the present study was to investigate the effects of preoperative fractioned irradiation using an electron beam on the healing process of colocolonic anastomoses in rats that underwent early and late surgical intervention.

\section{Methods}

Study was approved by the Research Ethics Committee of the Federal University of Sao Paulo (CEP UNIFESP Project No. 0159/07).

Thirty Wistar rats were randomly distributed into three groups of 10 animals each: group A (anastomosis without irradiation); group B (fractioned irradiation and early implementation of the anastomosis, seven days after the last irradiation); group C (fractioned irradiation and late implementation of the anastomosis 30 days after the last irradiation)

The anesthetic procedure used ketamine hydrochloride $\left(\right.$ Ketalar $\left.^{\circledR}\right)$ at a dose of $10 \mathrm{mg} / \mathrm{kg}$ and the sedative, analgesic and muscle relaxant 2-(2,6-xylidine)-5,6-dihydro-4H-1,3-thiazine hydrochloride $\left(\right.$ Rompun $^{\circledR}$ ) at a dose of $0.1 \mathrm{mg} / \mathrm{kg}$, and was uniform to all the animals. After anesthesia, irradiation was administered with the animal in a supine position. The field to be irradiated was determined at a distance of at least $50 \mathrm{~mm}$ from the genitalia, by means of illuminating the area (Figure 1).

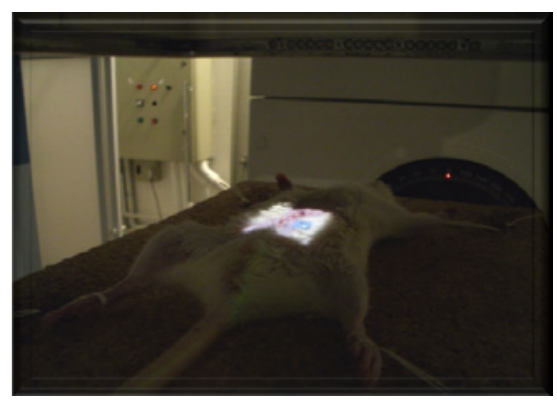

FIGURE 1 - Irradiation field illuminated.

The equipment used for the sessions was a Siemens Mevatron $\mathrm{MXE}^{\circledR}$ linear accelerator. The total dose calculated for the study was $660 \mathrm{cGy}$, which was administered as fractioned doses of 165 cGy, applied once a week, on four consecutive weeks. The final irradiation calculated for a $6 \mathrm{MV}$ device was 660 cGy, which had the biological equivalence of a total dose of 4,500 cGy applied on a daily basis of 225 cGy, five days a week for four consecutive weeks.

The animals in group B underwent the surgical procedure on the seventh day after finishing the four sessions of irradiation, while the animals in group $\mathrm{C}$ underwent surgery on the $30^{\text {th }}$ day after finishing the irradiation. The control group (group A) underwent 
surgical intervention together with group B. All the animals underwent the anesthesia described above. The incision was made $5 \mathrm{~cm}$ above the anal margin. After transversally sectioning the colon using scissors, the edges were repaired and anastomosis was carried out in a single layer, with a total of eight separate stitches using Vicryl ${ }^{\circledR} 6-0$, always beginning at the cardinal points (Figure 2 ). The incision was closed in layers, with a continuous stitch using nylon 4-0.

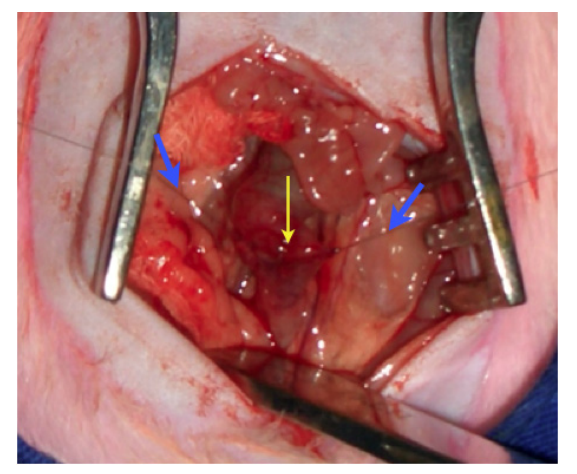

FIGURE 2 - Repair stitches (blue arrows) and anastomosis (yellow arrow) using vicryl 6-0.

For the evaluation under the microscope, sections of 5 microns in thickness were obtained from the surgical specimen in the areas of intense inflammatory process near the line of the anastomosis. Each slide was prepared bearing two sections from the specimen, such that a total of three slides per staining per animal were prepared. From these, the number of cells/ $\mu \mathrm{m}^{2}$ per animal was obtained. The histological analysis and the evaluation of the amount of collagen were carried out by means of computerized morphometry, using the Axionvision Imagelab $2000^{\circledR}$ software (Figure 3). These analyses were performed by an independent observer who was blinded regarding the identity of the groups analyzed.

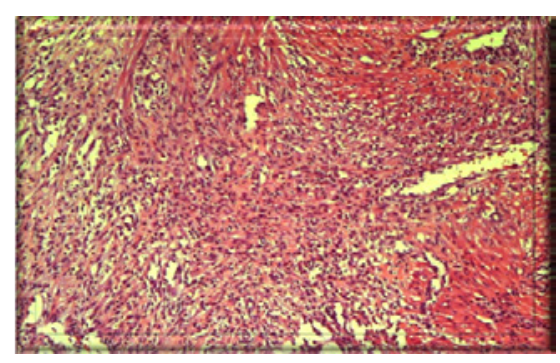

FIGURE 3 - Photomicrograph of the anastomosis area, at magnification 40x; optical microscopy with $\mathrm{H}$ staining, showing the inflammatory process at the healing area.

To analyze the results, Student's t test, Fisher's exact test and variance analysis were applied.

\section{Results}

Four animals died due to the anesthesia and surgical procedure, three in the pilot group and one in the $\mathrm{C}$ group. During evaluation of the bursting pressure of the colon wall, all animals were found to present the section on the line of the anastomosis. Four animals (one from the control group, two from group B and one from group C) presented rupture of the anastomosed area occurring just by manipulating the segment. The statistical analysis did not show any significant differences among groups $\mathrm{A}, \mathrm{B}$ and $\mathrm{C}$, i.e. between the control group and the groups that underwent irradiation (Table 1).

TABLE 1 - Distribution of the frequencies of anastomosis bursting pressures among the study groups.

\begin{tabular}{c|c|c|c}
\hline GROUP & $\begin{array}{c}\text { Ruptured by } \\
\text { manipulation }\end{array}$ & $\begin{array}{c}\text { Ruptured with } \\
\text { pressure less than } \\
\mathbf{1 0 0} \mathbf{~ m m H g}\end{array}$ & $\begin{array}{c}\text { Ruptured with } \\
\text { pressure more } \\
\text { than } \mathbf{1 0 0} \mathbf{~ m m H g}\end{array}$ \\
\hline A & 1 & 0 & 8 \\
\hline B & 2 & 2 & 5 \\
\hline C & 1 & 2 & 5 \\
\hline
\end{tabular}

Fisher's exact test $\mathrm{p}=0.42$

Regarding the cellularity of the inflammatory process, the computerized histological analysis showed that group A presented a mean of 0.0048 cells $/ \mu^{2}$, with a standard deviation of 0.00073 and variance of 0.00000055 . In group $B$, the mean was 0.0054 cells $/ \mu \mathrm{m}^{2}$, with a standard deviation of 0.00093 and variance of 0.0000008 . In group $\mathrm{C}$, the mean observed was 0.0073 cells $/ \mu \mathrm{m}^{2}$, with a standard deviation of 0.0011 and variance of 0.0000012 . All groups presented normal distribution (Table 2).

When compared between each other, groups A and B did not present statistically significant variations. However, the comparison between the control group (A) and group $\mathrm{C}$ showed significant values, with greater cellularity in the inflammatory process of group $\mathrm{C}$. When comparing groups $\mathrm{A}$ and $\mathrm{C}$ and groups $\mathrm{B}$ and $\mathrm{C}$, significant differences were observed among them, with greater numbers of cells in group C (Table 3). 
Effects of preoperative irradiation using fractioned electron beam on the healing process of colocolonic anastomosis in rats undergoing early and late surgical intervention

TABLE 2 - Distribution of the cellularity values for the animals in groups A and C, expressed as mean values and respective standard deviations.

\begin{tabular}{|c|c|c|c|c|c|c|c|c|c|c|c|c|}
\hline \multirow[t]{2}{*}{ Group } & Mean & Standard & Variance & \multicolumn{9}{|c|}{ Animal } \\
\hline & & & & A1 & A2 & A3 & A4 & A5 & A7 & A8 & A9 & A10 \\
\hline \multirow[t]{2}{*}{$\mathbf{A}$} & 0.0048 & 0.0073 & 0.00000055 & 0.0051 & 0.0043 & 0.0052 & 0.0032 & 0.0059 & 0.0048 & 0.0049 & 0.0050 & 0.0053 \\
\hline & & & & $\mathrm{C} 1$ & $\mathrm{C2}$ & $\mathrm{C3}$ & $\mathrm{C} 4$ & $\mathrm{C} 5$ & C6 & $\mathrm{C} 8$ & C9 & C10 \\
\hline C & 0.0073 & 0.0011 & 0.0000012 & 0.0073 & death & 0.0076 & 0.0076 & 0.0053 & 0.0066 & 0.0073 & 0.0089 & 0.0086 \\
\hline
\end{tabular}

$\mathrm{p}=0.000064^{*}$

TABLE 3 - Distribution of the cellularity values for the animals in groups B and C, expressed as mean values and respective standard deviations.

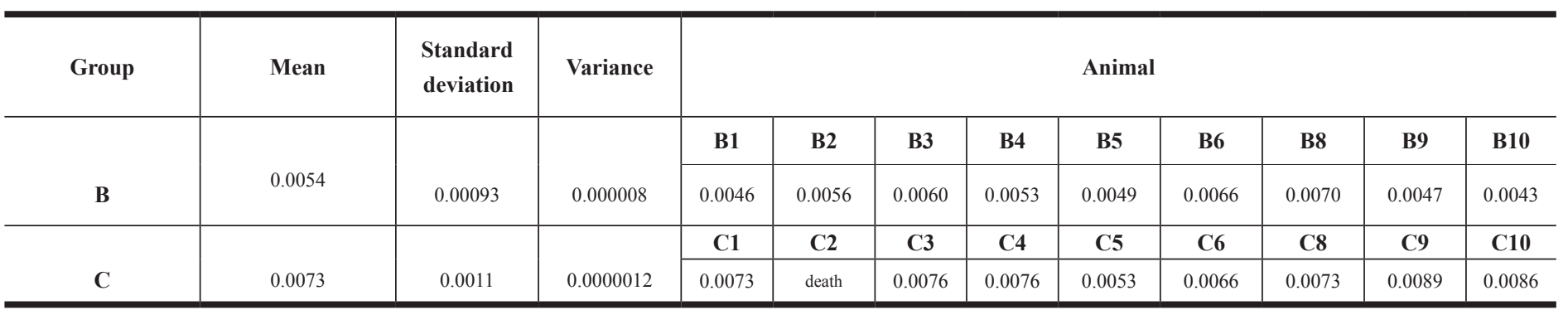

$\mathrm{p}=0.0015^{*}$

The mean collagen volume found in group A was 0.85, collagen volume was 0.54 , with SD of 0.3 and variance of 0.09 . with a standard deviation (SD) of 0.66. The variance observed in When compared, the collagen analysis did not show statistically this group was 0.4. In group B, the mean collagen volume was 0.40 , significant differences among the groups (Tables 4, 5 and 6).

with SD of 0.19 and variance of 0.04 ; and in group $\mathrm{C}$, the mean

TABLE 4 - Distribution of the collagen volume for the animals in groups A and B, expressed as mean values and respective standard deviations.

\begin{tabular}{|c|c|c|c|c|c|c|c|c|c|c|c|c|}
\hline Group & Mean & Standard & Variance & & & & & nimal & & & & \\
\hline \multirow[t]{2}{*}{ A } & \multirow[b]{2}{*}{0,85} & \multirow[b]{2}{*}{0,66} & \multirow[b]{2}{*}{0,4} & A1 & A2 & $\mathbf{A 3}$ & A4 & A5 & A7 & A8 & A9 & A10 \\
\hline & & & & 2,35 & 1,33 & 0,93 & 0,38 & 0,37 & 0,55 & 0,42 & 0,92 & 0,33 \\
\hline \multirow[t]{2}{*}{ B } & \multirow[b]{2}{*}{0,40} & \multirow[b]{2}{*}{0,19} & \multirow[b]{2}{*}{0,04} & B1 & B2 & B3 & B4 & B5 & B6 & B8 & B9 & B10 \\
\hline & & & & 0,72 & 0,32 & 0,67 & 0,22 & 0,13 & 0,50 & 0,37 & 0,45 & 0,27 \\
\hline
\end{tabular}

$\mathrm{p}=0.074$

TABLE 5 - Distribution of the collagen volume for the animals in groups A and C, expressed as mean values and respective standard deviations.

\begin{tabular}{|c|c|c|c|c|c|c|c|c|c|c|c|c|}
\hline Group & Mean & Standard & Variance & & & & & Inimal & & & & \\
\hline \multirow[t]{2}{*}{$\mathbf{A}$} & \multirow[b]{2}{*}{0,85} & \multirow[b]{2}{*}{0,66} & \multirow[b]{2}{*}{0,4} & A1 & A2 & $\mathbf{A 3}$ & A4 & A5 & $\mathbf{A} 7$ & A8 & A9 & $\mathbf{A 1 0}$ \\
\hline & & & & 2,35 & 1,33 & 0,93 & 0,38 & 0,37 & 0,55 & 0,42 & 0,92 & 0,33 \\
\hline \multirow[t]{2}{*}{ C } & \multirow[b]{2}{*}{0,54} & \multirow[b]{2}{*}{0,3} & \multirow[b]{2}{*}{0,09} & C1 & $\mathrm{C} 2$ & $\mathrm{C} 3$ & $\mathrm{C} 4$ & $\mathrm{C} 5$ & C6 & $\mathrm{C} 8$ & C9 & $\mathrm{C10}$ \\
\hline & & & & 0,48 & death & 0,66 & 0,62 & 0,48 & 0,33 & 0,17 & 0,35 & 0,50 \\
\hline
\end{tabular}

$\mathrm{p}=0.14$ 
TABLE 6 - Distribution of the collagen volume for the animals in groups B and C, expressed as mean values and respective standard deviations.

\begin{tabular}{|c|c|c|c|c|c|c|c|c|c|c|c|c|}
\hline Group & Mean & Standard & Variance & & & & & Inimal & & & & \\
\hline \multirow[t]{2}{*}{ B } & \multirow[b]{2}{*}{0,40} & \multirow[b]{2}{*}{0,19} & \multirow[b]{2}{*}{0,04} & B1 & B2 & B3 & B4 & B5 & B6 & B8 & B9 & B10 \\
\hline & & & & 0,72 & 0,32 & 0,67 & 0,22 & 0,13 & 0,50 & 0,37 & 0,45 & 0,27 \\
\hline \multirow[t]{2}{*}{$\mathrm{C}$} & \multirow[b]{2}{*}{0,54} & \multirow[b]{2}{*}{0,3} & \multirow[b]{2}{*}{0,09} & C1 & C2 & C3 & $\mathrm{C} 4$ & C5 & C6 & C8 & C9 & $\mathrm{C} 10$ \\
\hline & & & & 0,48 & death & 0,66 & 0,62 & 0,48 & 0,33 & 0,17 & 0,35 & 0,50 \\
\hline
\end{tabular}

$\mathrm{p}=0.46$

\section{Discussion}

The use of neoadjuvant therapy in cases of malignant rectal neoplasia has been under discussion for many years. The initial surgical results, dating from the 1950s, showed high incidence of local recurrences, with severely compromised quality of life. These recurrences led to the death of the patients.

Tumor reduction achieved through preoperative radiotherapy allows surgeons to carry out wide and safe resections of the neoplasia, especially at its radial margins. This method is also effective in preventing locoregional recurrences, because it has the capacity to sterilize the tumor cells that are commonly present in the perirectal tissue ${ }^{2}$.

Reis Neto et al. ${ }^{2}$ demonstrated that use of fractioned preoperative radiotherapy at a total dose of 4,000 cGy caused changes to tumor cell behavior, thereby increasing the number of differentiated cells by up to $44 \%$. Preoperative radiotherapy has also been shown to be more effective than postoperative radiotherapy at equivalent doses, because the blood flow and consequently the cell oxygenation are preserved, thus favoring up to three times more occurrences of cell apoptosis among the neoplastic cells ${ }^{12}$.

Recently, the Brazilian College of Surgeons published a consensus bulletin on malignant rectal infirmities, in which neoadjuvant therapy was recommended for some types of tumors.

However, there is no consensus regarding the length of the interval between the end of the radiotherapy and the surgical operation. The discussion about the length of this interval is based on the inherent risks of complications of the colorectal anastomosis and on the efficiency of involution of the tumor tissue. The morbidity relating to associate therapies seems to be lower when such therapy is carried out prior to the surgical operation ${ }^{13}$.

The animals in the control group and those that underwent surgery with an interval of seven days after the end of the irradiation presented similar mean cellularity values, as well as similar collagen concentrations.

It was observed that the animals that underwent the late surgical procedure presented increased cellularity, although no significant change in collagen concentration was found through this method.

This information is corroborated by the findings of Biert et al. ${ }^{14}$, who demonstrated through experimental models that there were no significant differences between the collagen concentrations in the anastomosis area. However, conclusions solely based on collagen concentrations need to be considered with caution, because these concentrations may be influenced by substances other than collagen ${ }^{15}$.

Since there is no standardization of any adequate analysis for structurally qualifying collagen molecules and correlating these characteristics with the resistance of the anastomosis, the current studies may demonstrate some degree of bias. Experimental studies that mention the bursting pressure of the anastomosis have only taken into account the mechanical force exerted on $\mathrm{it}^{16}$.

Activation of metalloproteinases interferes with the degradation of the extracellular matrix and, according to Seifert et $a l .{ }^{17}$, may be directly related to the tension strength of the anastomosis and its possible dehiscence.

Steirfert et al. ${ }^{18}$ and $\mathrm{Kuzu}$ et $a .^{19}$ made similar observations in studies on rats, in which their first group underwent intraoperative radiotherapy over the anastomosis line and the second underwent external radiotherapy consisting of a single dose over the left colon. Both authors observed a decrease in the amount of collagen in the anastomosis area.

However, these findings were not in agreement with those of Weiber et $a l .{ }^{20}$, who studied rats undergoing irradiation and did not demonstrate any significant alterations in the collagen concentrations at the anastomosis line between the control group and the experimentation group. 
It is also important to emphasize that, due to methodological variations in observation and assessment of the inflammatory and healing processes (represented by cellularity), as well as in quantification of the collagen concentrations in the animal experimentation models presented in the literature, extrapolation of results and comparisons with other animal models need to be done sparingly.

\section{Conclusion}

Fractioned irradiation on the colorectal tissue of the animals used promoted a greater cellular inflammatory reaction when the surgical procedure and the anastomosis were carried out at a later stage. This result did not cause any increase in the observed complications, nor did it influence the expected outcome, thus achieving similar results from a clinical point of view.

\section{References}

1. Heald R, Moran B, Ryall R, Sexton R, MacFarlane JK. Rectal cancer: the basingstoke experience of total mesorectal excision, 1978-1997. Arch Surg. 1998;133(8):894-8.

2. Reis Neto J, Quilici FA, Reis JA Jr. A comparison of nonoperative vs. preoperative radiotherapy in rectal carcinoma: a 10-year randomized trial. Dis Colon Rectum. 1989;32(8):702-10.

3. [No authors listed]. Improved survival with preoperative radiotherapy in resectable rectal cancer. Swedish Rectal Cancer Trial. N Engl J Med. 1997;336(14):980-7.

4. Bujko K. Timing of surgery following preoperative therapy in rectal cancer: there is no need for a prospective randomized trial. Dis Colon Rectum. 2012;55(3):e31.

5. Pettersson D, Holm T, Iversen H, Blomqvist L, Glimelius B, Martling A. Preoperative short-course radiotherapy with delayed surgery in primary rectal cancer. Br J Surg. 2012;99(4):577-83.

6. Centeno Neto AA, Barone B. Tratamento cirúrgico do cancer do reto: o que há de novo? Acta Cir Bras. 1990;5(3):109-16.

7. Marijnen CA, Kapiteijn E, van de Velde CJ, Martijn H, Steup WH, Wiggers T, Kranenbarg EK, Leer JW; Cooperative Investigators of the Dutch Colorectal Cancer Group. Acute side effects and complications after short-term preoperative radiotherapy combined with total mesorectal excision in primary rectal cancer: report of a multicenter randomized trial. J Clin Oncol. 2002;20(3):817-25.

8. Lopes-Paulo F. Efeitos da irradiação com raios-X em anastomoses colônicas: estudo estereológico experimental em ratos. Acta Cir Bras. 2004;19:504-10.

9. Stevens KJ, Fletcher W, Allen C. Anterior resection and primary anastomosis following high dose preoperative irradiation for adenocarcinoma of the recto-sigmoid. Cancer. 1978;41(5):2065-71.

10. Anseline PF, Lavery IC, Fazio VW, Jagelman DG, Weakley FL. Radiation Injury of the rectum: evaluation of surgical treatment. Ann Surg. 1981;194(6):716-24.

11. Mohiuddin M, Marks J, Marks G. Management of rectal cancer: short- vs. long-course preoperative radiation. Int J Radiat Oncol Biol Phys. 2008;72(3):636-43.

12. Habr-Gama A, Perez RO, Nadalin W, Nahas SC, Ribeiro U Jr, Silva E Sousa AH Jr, Campos FG, Kiss DR, Gama-Rodrigues J. Long- term results of preoperative chemoradiation for distal rectal cancer correlation between final stage and survival. J Gastrointest Surg. 2005;9(1):90-9.

13. Habr-Gama A, de Souza PM, Ribeiro U Jr, Nadalin W, Gansl R, Sousa AH Jr, Campos FG, Gama-Rodrigues J. Low rectal cancer: impact of radiation and chemotherapy on surgical treatment. Dis Colon Rectum. 1998;41(9):1087-96.

14. Biert J, Hoogenhout J, Wobbes T, Hendriks T. High-dose preoperative irradiation without detrimental effect on early repair of anastomoses in the colon of the rat. Radiat Res. 1997;147(3):362-8.

15. Hendriks T, Mastboom W. Healing of experimental intestinal anastomoses. Parameters for repair. Dis Colon Rectum. 1990;33(10):891-901.

16. Wu FC, Ayrizono MLS, Fagundes JJ, Coy CSR, Góes JRN, Leonardi LS. Estudos biomecânicos da ação de aderências sobre anastomose cólica: trabalho experimental em ratos. Acta Cir Bras. 2003;18(3):216-23.

17. Seifert WF, Wobbes T, Hendricks T. Divergent patterns of matrix metalloproteinase activity during wound healing in ileum and colon of rats. Gut. 1996;39(1):114-9.

18. Seifert WF, Wobbes T, Hoogenhout J, de Man BM, Huyben KM, Hendriks T. Intraoperative irradiation delays anastomotic repair in rat colon. Am J Surg. 1995; 170(3):256-61.

19. Kuzu MA, Koksoy C, Akyol FH, Uzal D, Kale T, Demirpence E. Effects of preoperative fractionated irradiation on left colonic anastomoses in the rat. Dis Colon Rectum. 1998;41(3):370-6

20. Weiber S, Jiborn H, Zederfeldt B. Preoperative irradiation and colonic healing. Eur J Surg. 1994;160(1):47-51.

\section{Acknowledgement}

The authors thank for the researches of the Radium Institute of Campinas.

\section{Correspondence:}

Joaquim Simões Neto

Departamento de Clínica Cirúrgica-PUCCAMP

Rua John Body Dunlop, s/n

13060-904 Campinas - SP Brasil

jsimoes@uol.com.br

Received: August 23, 2012

Review: October 24, 2012

Accepted: November 20, 2012

Conflict of interest: none

Financial source: none

${ }^{1}$ Research performed at Laboratory of Surgical Techniques, Pontifical Catholic University of Campinas (PUCCAMP), Sao Paulo, Brazil. Part of Master degree thesis, Postgraduate Program in Surgical Gastroenterology, Federal University of Sao Paulo (UNIFESP). Tutor: Prof. Delcio Matos. 